\title{
LUDOPEDAGOGIA: CONTRIBUIÇÕES NA EDUCAÇÃO INFANTIL
}

\author{
Greice Kely Santos Silva ${ }^{1}$
}

RESUMO: O presente artigo tem como objetivo apresentar as contribuições que a Ludopedagogia oferece como recurso de aprendizagem na Educação Infantil. Nessa perspectiva, abordamos métodos de atividades lúdicas que podem favorecer ao desenvolvimento intelectual infantil. Ressaltamos a importância da família como peça fundamental para que essa interação do aluno com a escola estabeleça resultados positivos, para a vida escolar do aluno. Além disso, enfatizamos que a inclusão das crianças com necessidades especiais na prática da ludicidade em grupo, engloba os fatores de engajamento, inclusão e desenvolvimento cognitivo, contribuindo para aprendizagem das crianças independentemente de suas especificidades e limitações. $O$ trabalho com a ludicidade na Educação Infantil funciona como um método eficaz de ensino, tornando o aprendizado mais prazeroso e eficaz.

Palavras-chave: Ludopedagogia. Educação Infantil. Inclusão. Aprendizagem.

ABSTRACT: This article aims to present the contributions that Playful Pedagogy offers as a learning resource in Early Childhood Education. From this perspective, we approach methods of playful activities that can favor children's intellectual development. We emphasize the importance of the family as a fundamental part for this interaction between the student and the school to establish positive results for the student's school life. In addition, we emphasize that the inclusion of children with special needs in the practice of playfulness in a group includes the factors of engagement, inclusion and cognitive development, contributing to children's learning regardless of their specificities and

\footnotetext{
I Graduada em Pedagogia. MBA em Gestão de Pessoas e Psicologia Organizacional. Especialista em Ludopedagogia e Educação Infantil. Atualmente, trabalho como Supervisora Pedagógica em uma Escola Privada, voltada para Educação Básica e Profissionalizante na cidade de Aracaju/SE. CV:http://lattes.cnpq.br/3834950288603373. E-mail: reicekely_silva@hotmail.com.
} 
limitations. The work with playfulness in Early Childhood Education works as an effective teaching method, making learning more enjoyable and effective.

Keywords: Playful Pedagogy. Child education. Inclusion. Learning.

\section{INTRODUÇÃO}

$\mathrm{O}$ ato de brincar pode ser considerado como principal fator de desenvolvimento cognitivo infantil. Isso porque essa ação, contribui positivamente para potencialização dos aspectos físico, moral, motor, emocional, intelectual e psicossocial da criança.

Com os jogos e brincadeiras, a criança expressa seus interesses, refletem e experimentam situações do seu cotidiano que contribuem para trocas de experiências.

Vale ressaltar que o estímulo da ludicidade infantil deve ser iniciado no contexto familiar, visto que essas ações contribuem no aspecto de desenvolvimento intelectual e motor antes mesmo da criança iniciar suas atividades escolares.

Segundo o RCNEI vol.or (1998, p.27) A brincadeira favorece a autoestima das crianças, auxiliando-as a superar progressivamente suas aquisições de forma criativa. Brincar contribui, assim, para a interiorização de determinados modelos de adulto, no âmbito de grupos sociais diversos. Essas significações atribuídas ao brincar transformam-no em um espaço singular de constituição infantil.

A educação infantil é a primeira etapa escolar, na qual a criança é inserida, mediante um processo de instrução e familiarização, contribuindo para o fortalecimento das relações interpessoais.

Além disso, alguns estudos comprovam que aprender brincando, auxilia $30 \%$ a mais na absorção da aprendizagem do que de forma tradicional. Portanto, analisar a forma didática de trabalho é um fator importante para solucionar déficit na prática educativa, pois o principal objetivo deve ser facilitar o desenvolvimento cognitivo dos alunos.

Atividades lúdicas e motoras são consideradas relevantes mediante a prática da ludicidade uma vez que elas fazem parte da rotina dos discentes de forma bastante efetiva na educação infantil. 
O brincar não é apenas a finalidade do processo, mas também o meio utilizado para favorecer os diversos tipos de aprendizagens.

Dentro desse contexto destacamos o papel da ludicidade no desenvolvimento cognitivo das crianças com necessidades educacionais. Visto que elas têm o direito de participar e aprender de forma igualitária, devendo ser descartado qualquer tipo de exclusão social.

A inclusão social é um fator determinante que colabora para o desenvolvimento cognitivo das crianças com déficit de aprendizagem e/ou qualquer outro tipo de necessidades especiais.

Nessa perspectiva, o presente artigo tem como finalidade explicitar as contribuições da Ludopedagogia para desempenho cognitivo da criança na Educação Infantil, sugerindo habilidades que auxiliem na prática educativa, visando uma aprendizagem significativa, prazerosa e eficiente.

Atividades voltadas para metodologias ativas na educação, contribui para o protagonismo do educando, pois torna-o participante da prática educativa. Além de estimular o aprendizado, raciocino lógico, independência e o trabalho em equipe.

A Ludopedagogia para o docente é um recurso que favorece o ensino-aprendizagem dos alunos, conforme envolvimento e construção de saberes. Educar nesse contexto, vai além da transferência de conceitos, pois enfatiza no educando, diversas formas de pensar, abrangendo um leque de informações para ampliação do repertório sociocultural.

\section{A LUDICIDADE COMO MÉTODO DE APRENDIZAGEM}

A palavra, lúdico tem a sua etimologia latina "ludus" que faz referência a "jogo". Com o passar do tempo, a ludicidade passou a possibilitar interações e contribuir para o desenvolvimento psíquico, físico e motor. Pois através das atividades lúdicas (jogos e brincadeira), a criança forma conceitos, ideias, buscam a empatia, criam relações, compartilham experiências, contribuindo para a melhoria das relações de cognição e vivências. 


\begin{abstract}
A ludicidade não é apenas uma forma de diversão, ela tornou-se uma necessidade do ser humano em qualquer idade. Ao desenvolver atividade com aspectos lúdicos possibilita e facilita a aprendizagem, o desenvolvimento pessoal, social e cultural, colabora para uma boa saúde mental, prepara para um estado interior fértil. No desenvolver das ações lúdicas percebe-se que ela auxilia no processo de socialização, comunicação, expressão e construção do conhecimento, pois possibilitam experiências que constroem valores também para aspectos pessoas (Freire, 20II, p.4I e 42).
\end{abstract}

A ludicidade é um instrumento metodológico muito rico, pois ao ser trabalhado com as crianças seja em casa junto aos pais ou na escola com os educadores, possibilita uma relação de liberdade e estímulo da criança com o mundo externo, contribuindo para a formação individual da criança.

Os procedimentos metodológicos utilizados pelo professor são peças-chave na motivação dos alunos. A metodologia deve constar de técnicas específicas, que estimulem o aluno em todos as esferas de seu comportamento humano (motora, cognitiva, afetiva e social), possibilitando a criança inúmeras vivências (Freire, 2008, p.153).

Além disso, ao levar em conta os recurso pedagógicos que visam o bem-estar e evolução na aprendizagem infantil, a prática educativa deve sempre levar em consideração a cultura própria de cada criança. Suas crenças, costumes, hábitos e experiências.

O lúdico como recurso pedagógico direcionado às áreas de desenvolvimento e aprendizagem pode ser muito significativo no sentido de encorajar as crianças a tomar consciência dos conhecimentos sociais que são desenvolvidos durante o jogo, os quais podem ser usados para ajudá-las no desenvolvimento de uma compreensão positiva da sociedade e na aquisição de habilidades. (RAU, 20II, p.II2).

Nessa perspectiva ao considerar os conhecimentos prévios e a cultura de cada criança é importante salientar a relevância do ato de brincar dentro e fora do contexto escolar. Isso porque o fato de a criança brincar na rua ou em outros espaços não escolares, contribui para um aprendizado natural pois é na interação com seus pares que a criança evolui.

A brincadeira na rua ou em outros espaços abertos tem várias implicações (não considerando a questão da falta de segurança), já que a criatividade das crianças toma conta dos espaços e os transforma em função das suas "necessidades lúdicas". Brincar na rua é um aprendizado e uma oportunidade para a criança interagir com outros parceiros e desenvolver jogos nos quais a atividade física predomina. (Friedmann, 1996, p.15).

Seja na escola, na rua ou dentro de casa, a família deve estimular a ludicidade, pois tal estímulo auxilia na evolução da criança ao chegar na escola, visto que, esse suporte é algo 
determinante para proporcionar uma evolução considerável no crescimento intelectual da criança.

\footnotetext{
O espaço reservado à atividade lúdica da criança dentro de casa (quando ele existe) muda de um contexto para o outro, podendo ser um quarto só para jogos, um quintal, um pátio, a área comum de um condomínio e outros. Dentro de suas possibilidades, a criança "transforma" esses espaços para adaptá-los a sua brincadeira. (Friedmann,1996, p. 15)
}

Desta forma, vale ressaltar que a Ludopedagogia é um método que visa a aprendizagem de uma forma mais leve e dinâmica. Com um foco principal: contribuir para o ensino-aprendizagem, considerando sempre a "bagagem dos alunos". Esta por sua vez necessita ser considerada em sua forma integral, ou seja, deve ser enfatizado suas experiências escolares e domiciliar.

\section{A INFLUÊNCIA DO JOGO, BRINQUEDO E BRINCADEIRA NA APRENDIZAGEM INFANTIL}

O Ato de brincar corrobora para uma aprendizagem mais significativa pois a criança acaba assimilando e acomodando informações importantes de forma leve e divertida.

Para Freidmann (1996, p I4), “o jogo implica para a criança muito mais do que o simples ato de brincar. Através do jogo, ela está se comunicando com o mundo e também está se expressando”.

Kishimoto (1997) levanta uma reflexão importante sobre o papel do jogo como caráter educativo:

\footnotetext{
Ao permitir a manifestação do imaginário infantil, por meio de objetivos simbólicos dispostos intencionalmente, a função pedagógica subsidia o desenvolvimento integral da criança. Neste sentido, qualquer jogo empregado na escola, desde que respeite a natureza do ato lúdico, apresenta caráter educativo e pode receber também a denominação geral de jogo educativo (KISHIMOTO, 1997, P.9o).
}

O jogo e brincadeira dentro da perspectiva educacional, devem ser considerados como instrumentos das metodologias ativas. Devem ser vistos como meios para atingir objetivos predefinidos. Através dos jogos e brincadeiras podemos avaliar o nível cognitivo do aluno, trabalhar conteúdos transversais e curriculares, buscando agregar uma aprendizagem coletiva e ao mesmo tempo individualizada, visando estimular a evolução integral de cada criança. 
Brincar é, assim, um espaço no qual se pode observar a coordenação das experiências prévias das crianças e aquilo que os objetos manipulados sugerem ou provocam no momento presente. Pela repetição daquilo que já conhecem, utilizando a ativação da memória, atualizam seus conhecimentos prévios, ampliando-os e transformando-os por meio da criação de uma situação imaginária nova. Brincar constitui-se, dessa forma, em uma atividade interna das crianças, baseada no desenvolvimento da imaginação e na interpretação da realidade, sem ser ilusão ou mentira. (RCNEI vol.o2, 1998, p.23).

Outro aspecto relevante dentro da ludicidade é o trabalho da musicalidade dentro desse contexto. Pois a música está presente em diversas atividades desenvolvidas na escola, dentre elas podemos citar brincadeiras cantadas, rimas, paródias ente outras.

$\mathrm{O}$ ambiente sonoro, assim como a presença da música em diferentes e variadas situações do cotidiano fazem com que os bebês e crianças iniciem seu processo de musicalização de forma intuitiva. Adultos cantam melodias curtas, cantigas de ninar, fazem brincadeiras cantadas, com rimas, parlendas etc., reconhecendo o fascínio que tais jogos exercem. (RCNEI vol. 3, 1998, p.5I)

Para Freire (2008, p.155): As principais ferramentas ludo-educativas são os jogos, as histórias, as dramatizações, as músicas, danças e canções e as artes plásticas. Cada uma dessas ferramentas tem possibilidades particulares de desenvolvimento e aprendizagem. $\mathrm{O}$ uso combinado de todas elas gera o processo integrado de um método educacional que vai muito além da simples transmissão de conteúdo, pois forma para a vida e para o mundo.

O brincar e o jogar não podem ser visualizados apenas como divertimento. Essas ações importantes e indispensáveis no que diz respeito ao lado emocional, cognitivo, linguístico e social da criança.

Os jogos e brincadeiras auxiliam no processo de ensino aprendizagem infantil pois contribuem para o desenvolvimento de habilidades como criatividade, motricidade, interpretação, agilidade, levantamento de hipóteses, organização, trabalho em equipe, tomada de decisão, formação de conduta ética e vários outros fatores que acabam refletindo positivamente na formação íntegra da criança, fazendo com que ela desenvolva suas potencialidades de forma integral.

Para Santos (20II, p. 23), a escola ludicamente inspirada não é aquela que realiza todas as atividades com jogos, mas aquela em que as características lúdicas influenciam o modo de ser do educador e interferem na organização do ambiente, na seleção das atividades e na visão que se tem de criança, jovem, adulto e idoso, enfim, do ser humano. 
O brinquedo é outro mecanismo que faz parte da ludicidade, pois oportuniza uma relação de autonomia da criança, deixando-a mais livre para estimular seu imaginário.

Segundo Kishimoto (1997, p.91), os brinquedos podem incorporar, também um imaginário preexistente criado pelos desenhos animados seriados televisivos, mundo da ficção cientifica com motores e robôs, mundo encantado dos contos de fada, estórias de piratas, índios e bandidos.

Cabe ao professor traçar estratégias de forma prévia visando conhecer melhor o seu aluno para que possa trabalhar com os jogos, brinquedos e brincadeiras de forma prática, inserindo essas atividades dentro dos conteúdos programáticos. Utilizar a ludicidade apenas nos momentos de intervalos e recreios fogem totalmente da proposta atual de interação.

\section{O PAPEL DA LUDOPEDAGOGIA NA ALFABETIZAÇÃO DAS CRIANÇAS COM NECESSIDADES EDUCACIONAIS}

A Ludopedagogia contribui para a socialização das crianças com necessidades educacionais especiais diante das demais crianças ditas "normais". Visto que, nesse contexto as atividades trabalhadas principalmente em grupos, contribui para a socialização, trabalha o cognitivo e possibilita o desenvolvimento escolar daqueles que tem maior dificuldade.

As crianças com necessidades educacionais especiais devem conviver com as outras no seu cotidiano e complexidade habitual, e não devem ser mantidas isoladas.

Independente do déficit de aprendizagem e da deficiência, toda criança tem condição de aprender. Ela vai aprender de uma forma diferenciada, dentro do tempo dela.

No espaço escolar deve ter espaço para todos. A educação inclusiva no espaço educacional abrange a todos, independentemente de raça, cultura, nível social, intelectual, identidade de gênero, nacionalidade, idade, sotaque, religião entre outros aspectos.

A LDBEN 9394/96, assinala como diretrizes: a inclusão, a valorização da diversidade, a flexibilidade, a qualidade e a autonomia, assim como, a competência para o trabalho e a cidadania. 
Já a Constituição Federal traz no seu Art. 6ำ a seguinte informação: são direitos sociais: a educação, a saúde, o trabalho, o lazer, a segurança, a previdência social, a proteção à maternidade e à infância, a assistência aos desamparados.

Ainda na Constituição no Art. 205: A educação é direito de todos e dever do Estado e da família, será promovida e incentivada com a colaboração da sociedade, visando ao pleno desenvolvimento da pessoa, seu preparo para o exercício da cidadania e sua qualificação para o trabalho.

Diante desse cenário mediante a inclusão dos alunos especiais na escola para sua evolução no processo de alfabetização, a Ludopedagogia entra como recurso multidisciplinar, contribuindo para o desenvolvimento motor e cognitivo dessas crianças através da interação com seus pares mediantes jogos e brincadeiras, contribuindo para uma aprendizagem significativa, mas sem pressão e cobranças externas.

Para Piaget (1987, p.6), "brincando a criança é capaz de assimilar o mundo exterior às suas próprias necessidades, mesmo sem se adaptar as realidades que estão a sua volta."

Segundo CORDAZZO; VIEIRA (200o, p. 94). Na sua influência para com o desenvolvimento infantil o brincar pode ser utilizado como uma ferramenta para estimular déficits e dificuldades encontradas em alguns aspectos desenvolvimentais. Entretanto, os profissionais que lidam com estas crianças devem estar atentos ao desenvolvimento global infantil e não se deterem a aspectos isolados, uma vez que todos os aspectos estão interligados e exercem influências uns para om os outros.

É necessário mediadores e profissionais qualificados, que tenham habilidades para elaborar recursos pedagógicos apropriados e que sabiam realizar atividades lúdicas preferencialmente em salas de Atendimento Educacional Especializado (AEE), visando uma maior assimilação das atividades educativas.

Para Oliveira, (2011, p. 252), considera-se, hoje que a educação especial não pode ser olhada como um sistema paralelo à educação geral, e sim fazer parte dela como um conjunto de recursos pedagógicos e de serviços de apoio que facilitem a aprendizagem de todos em turma regulares.

A escola deve sempre trabalhar seu currículo com atividades voltadas para ludicidade pois viabiliza aos alunos momentos de diversão, percepção, autonomia, autoconhecimento, desenvolvimento da linguagem, desenvolvimento mental, respeito as diferenças e empatia. 
Piaget (1975, p.47) afirma que "os jogos estão diretamente ligados ao desenvolvimento mental da infância; tanto a aprendizagem quanto as atividades lúdicas constituem uma assimilação do real”.

Com a ludicidade é possível realizar vários jogos e brincadeiras com as crianças que tem necessidades especiais com o restante da turma. Claro que nem sempre o resultado irá sair conforme o esperado e cabe ao professor buscar estratégias para adaptações de atividade, buscando sempre um maior engajamento do grupo.

Diante desse contexto partimos para o pressuposto de que todos os aspectos abordados até o momento são de grande relevância para auxiliar na alfabetização dos alunos com necessidades especiais, porém o primeiro contato com a linguagem oral surge através da família.

O primeiro contato com a aprendizagem surge através dos laços familiares, que acabam influenciando a criança na construção dos saberes. A escola tem o papel de dar continuidade ao conhecimento e assimilação de novos conhecimentos, visando colaborar para o desenvolvimento integral do aluno.

Para Freire (20II, p.4I) “A ludicidade não é apenas uma forma de diversão, ela tornouse uma necessidade do ser humano de qualquer idade".

A ludicidade surgiu para ajudar a todos pois é através do lúdico que as crianças com necessidades educativas especiais conhecem a si mesmo e os outros, descobrem o mundo, exercitam toda a sua capacidade de percepção e ajuda na sua autoestima, melhora o seu desenvolvimento cognitivo, psicomotor e afetivo.

Além disso, a prática da ludicidade na alfabetização é fundamental para o desenvolvimento de habilidades e competências, pois é através dos jogos, musicalidade e brincadeiras que as crianças despertam o prazer em aprender.

Para isso é fundamental que o docente viabilize possibilidades de adaptações curricular, realizando um planejamento flexível e criativo, visando o crescimento educacional dos seus alunos independentemente de déficit de aprendizagem ou adaptações. 


\section{RESULTADOS E DISCUSSÕES}

Como a prática da ludicidade no cotidiano da educação infantil, percebemos que a atividade lúdica contribui positivamente para melhorar o desempenho escolar das crianças.

Aprender brincando é uma maneira de abordar os conteúdos de forma leve, consistente e efetiva, pois desperta na criança o interesse diante das descobres e criações.

Não podemos deixar de destacar a importância da relação entre a família e escola, visto que o trabalho realizado em sala de aula deve ter sua continuidade em casa. Esse apoio familiar é um ponto de discussão que preconiza alguns aspectos, dentre eles a falta de incentivo das famílias em realizar atividades lúdicas em detrimento das mídias digitais que viabilizam economia de tempo e disposição de interação.

Diante desse cenário é extremamente importante conscientizar os pais e responsáveis a respeito desse hábito que se tornou o mau do século: a troca do diálogo presencial pelo virtual, isso quando é possível.

Esse fato é muito comum nos perfis das famílias brasileiras e cabe a escola o papel de conscientizar a família sobre as consequências que essa conduta traz de forma prejudicial para o desenvolvimento intelectual da criança.

É um grande desafio para os docentes quebrar alguns "tabus" e lançar propostas inovadores para a família, porém não é impossível quando trabalhamos por amor a profissão.

\section{CONSIDERAÇÕES FINAIS}

Diante do que foi abordado, ressaltamos a importância da ludicidade na educação infantil, pois através das atividades lúdicas as crianças se tornam protagonistas do seu próprio conhecimento. Isso é possível por que devido ao contato com o mundo imaginário, elas desenvolvem suas habilidades cognitivas de forma divertida, tornando a aprendizagem prazerosa.

Vale destacar que após vários pesquisas de alguns estudiosos, a Ludopedagogia foi comprovada como uma técnica de ensino aliada ao docente, pois possibilita que seja 
trabalhado conteúdos e estratégias de ensino para públicos variados. Nessa perspectiva, podemos destacar que as atividades realizadas em sala de aula servem para crianças com necessidades especiais ou não, cabendo ao docente ter um olhar crítico diante das dificuldades de execução e/ou funcionalidades das atividades propostas.

Para que esse olhar inovador tenha um resultado satisfatório é necessário que se invista em formação continuada para professores, na busca de um aprendizado significativo. Onde o profissional de educação será orientado a como elaborar estratégias de socialização que contribuía para o enriquecimento intelectual dos educandos.

Atualmente inovar no ensino traz ganhos importantes para a socialização e inclusão nas escolas, pois aprender em grupo é muito mais prazeroso do que de forma individual.

Portanto o professor ao entender a importância de trabalhar a Ludopedagogia com seus alunos, ele estará colaborando para a valorização do desenvolvimento infantil de forma integral, seja ele: intelectual, físico, social, cognitivo e afetivo. Considerando a ludicidade como uma ferramenta transformadora na prática de ensino.

\section{REFERÊNCIAS BIBLIOGRÁFICAS}

CORDAZZO, Scheila Tatiana Duarte; VIEIRA, Mauro Luís. A brincadeira e suas implicações nos processos de aprendizagem e de desenvolvimento. Estud. pesqui. psicol., Rio de janeiro, $\mathbf{v}$ 7, n.I, junho 2007. Disponível em http://pepsic.bvsalud.org/scielo.php?script=sci_arttext\&pid=SI808-42812007000100009. Acesso em 13 de maio de 2021.

FREIRE, Ivete de Aquino. Lúdico, Movimento e Diálogo In: AZEVEDO, Tania Suely (org.). Reflexões e Sugestões Práticas para Atuação na educação Infantil. I a . ed. Campinas, 2008.

FREIRE, Patrícia de Oliveira. "A inclusão de crianças com necessidades educacionais em processo de alfabetização: O lúdico como recurso para aprendizagem". Universidade de Brasília, Brasilia, 20Ir. Disponível em: https://bdm.unb.br/handle/ı0483/3190 
KISHIMOTO, Tizuko M. Jogos, brinquedo, brincadeira e a educação. Org.3. ed. São Paulo: Cortez,1997.

OLIVEIRA, Zilma de Moraes Ramos de. "Educação Infantil: fundamentos e métodos". -7. Ed, - São Paulo: Cortez, 20II. - (Coleção Docência em Formação).

PIAGET, J. A formação do símbolo na criança: imitação, jogo e sonho, imagem e representação. 2.ed. Rio de Janeiro: Zahar, 1975.

RAU, Maria Cristina Trois Dorneles. "A ludicidade na educação: uma atitude pedagógica”. 2 ed. rev.,atual.e ampl.- Curitiba:Ibpex,20II.

Referencial curricular nacional para a educação infantil / Ministério da Educação e do Desporto, Secretaria de Educação Fundamental. - Brasília: MEC/SEF, 1998. Iv.: il.

Referencial curricular nacional para a educação infantil / Ministério da Educação e do Desporto, Secretaria de Educação Fundamental. - Brasília: MEC/SEF, 1998. 2v.: il.

Referencial curricular nacional para a educação infantil / Ministério da Educação e do 656 Desporto, Secretaria de Educação Fundamental. - Brasília: MEC/SEF, 1998. 3v.: il.

SANTOS, Santa Marli Pires dos. O brincar na escola: Metodologia Lúdico-vivencial, coletâneas de jogos, brinquedos e dinâmicas. 2 ed. Petrópolis, RJ: Vozes, 2011. 